\title{
OPEM
}

www.opem.org

Oriental Pharmacy and Experimental Medicine 2010 10(2), 51-58

DOI 10.3742/OPEM.2010.10.2.051

\section{Effects of Vitex rotundifolia on radical scavenging and nitric oxide production}

\author{
Jae Ki Choi ${ }^{1}$, Dong Seok Cha ${ }^{1}$, Yong Jae Lee ${ }^{1}$, Sung Hoon Ko ${ }^{1}$, Ho Jun Park ${ }^{1}$, Se Yeoun Lee ${ }^{1}$, \\ Jae Hyuk Choi ${ }^{1}$ and Hoon Jeon ${ }^{1,2, *}$ \\ ${ }^{I}$ Department of Oriental Pharmacy, College of Pharmacy, Woosuk University, Chonbuk, Republic of Korea; \\ ${ }^{2}$ Center for Healthcare Technology Development, Chonbuk, Republic of Korea
}

Received for publication March 10, 2010; accepted April 14, 2010

\begin{abstract}
SUMMARY
Vitex rotundifolia ( $V$. rotundifolia) has been used for treating headache, dizziness, toothache and removal of fever as a traditional medicine in Korea. In the present study, we examined the antioxidant and anti-inflammatory activities of $85 \%$ methanol extract of $V$. rotundifolia. In various radical scavenging assays, $V$. rotundifolia exhibited strong scavenging effect on 1, 1-diphenyl-2picrylhydrazyl free radical, superoxide radical, nitric oxide. To elucidate the anti-inflammatory properties of $V$. rotundifolia, we investigated the inhibition effects of nitric oxide production in IFN-gamma and LPS-stimulated mouse peritoneal macrophages. $V$. rotundifolia suppressed nitric oxide production, iNOS and COX-2 expression dose-dependently through suppression of NF-êB activation without notable cytotoxicity. These findings mean that $V$. rotundifolia may be beneficial in oxidative stress-mediated inflammatory disorders.
\end{abstract}

Key words: Vitex rotundifolia; Antioxidant; Anti-inflammatory

\section{INTRODUCTION}

Inflammation is a defense mechanism to minimize the damage by infection or irritation and may be referred to as the innate cascade including various cells and cytokines (Zamora et al., 2000). It is characterized by redness, heat, swelling, pain and dysfunction of the organs. Macrophages play a central role in host defense and maintenance as a major immune cell in inflammation since proinflammatory mediators such as nitric oxide (NO), prostagladins (PGs) and cytokines are secreted by activated macrophage.

NO produced by one of three kind of NO synthase

*Correspondence: Hoon Jeon, Department of Oriental Pharmacy, College of Pharmacy, Woosuk University, Chonbuk, Republic of Korea. Tel: +82632901577; Fax: +82632901576; E-mail: hoonj6343@hanmail.net
(NOS) that $\mathrm{nNOS}$ (neuronal NOS), endothelial NOS (eNOS), inducible NOS (iNOS) from L-arginine. $\mathrm{NO}$, produced by nNOS and eNOS in nanomolar concentration, play an important role as a neurotransmitter and vasodilator. However, overproduction of NO, mediated by iNOS, intimately correlated with the pathological conditions in inflammation related diseases (Wang et al., 2003). COX (cyclooxygenase), another key enzyme in inflammation, is the rate-limiting enzyme that catalyzes the formation of PGs from arachidonic acid. Levels of PGs increase early in the step of inflammation. Like NOS, COX also exists in both constitutive (COX-1) and inducible (COX-2) forms. It is well known that the COX-1 is a housekeeping protein in most tissues and it catalyzes the synthesis of PGs for normal physiological functions while COX-2 mediates an inflammatory response. It is well 
known that iNOS and COX-2 expression is predominantly regulated by the ubiquitously expressed NF- $\mathrm{kB}$ (nuclear factor kappa B) which is required for the inducible expression of genes associated with inflammatory responses. Therefore, attenuation of NF- $\mathrm{KB}$ activation may be a reasonable strategy to anti-inflammatory drugs.

During normal aerobic conditions, free radicals such as reactive oxygen species ( $\mathrm{ROS} ; \cdot \mathrm{O}_{2}^{-}, \cdot \mathrm{OH}$, $\mathrm{H}_{2} \mathrm{O}_{2}$ ) and reactive nitrogen species (RNS; $\bullet N O$, $\mathrm{HNO}_{2}, \mathrm{ONOO}^{-}$) generated. Especially the production of ROS and RNS in phagocytic leukocytes such as macrophages, neutrophils, monocytes is one of the important process in inflammation (D'Acquisto $e t$ al., 2002). Therefore, antioxidant may provide a therapeutic approach in cellular injury and dysfunction observed in inflammatory disorders (Conner and Grisham., 1996).

In Korea, Vitex rotundifolia ( $V$. rotundifolia) was traditionally used to counteract headache, fever, toothache and eye disease. It is well known that $V$. rotundifolia. has essential oil such as a-pinene, camphene, terpineol, acetylester diterpene alchol, diterpene of labdane type, diterpene of abietane type (Masateru et al., 2000) and flavonoid such as casticin and artemetin (Ono et al., 1999). V. rotundifolia have been found possess anti-leukemic (Ko et al., 2000), anti-inflammatory (Zhu et al., 1998) and antiallergic properties (Shin et al., 2000). In view of the several reports of $V$. rotundifolia described above, $V$. rotundifolia was proposed to have antioxidant and anti-inflammatory properties. Therefore, in this study we investigate the effect of the $V$. rotundifolia on the radical scavenging and inhibitory effect on inflammatory mediators such as NO, iNOS and COX-2 in rIFN- $\gamma$ and LPS stimulated murine peritoneal macrophages. To clarify the mechanism of iNOS suppression, we also assessed the effect of $V$. rotundifolia on the activation of NF-kB.

\section{MATERIALS AND METHODS}

Preparation of the stem and leaves of $V$. rotundifolia
The plant materials were purchased from Wansanyakupsa (Jeonju, South Korea) in March 2005. A voucher specimen (WME008) has been deposited at the Department of Oriental Pharmacy, College of Pharmacy, Woosuk University. The extract of $V$. rotundifolia was obtained twice from the dried sample $(250 \mathrm{~g})$ with $5,000 \mathrm{ml}$ of $85 \%$ $\mathrm{MeOH}$ under ultrasonification for $2 \mathrm{~h}$. It was evaporated and lyophilized to yield an $\mathrm{MeOH}$ extract of V. rotundifolia (Yield : 5.35\%), which was then stored at $-20^{\circ} \mathrm{C}$ until use.

\section{1, 1-diphenyl-2-picrylhydrasyl (DPPH) radical scavenging assay}

The scavenging effect of $V$. rotundifolia on DPPH radical was measured using the method of Gyamfi et al. (1999) with some modification. A $5 \mu$ aliquot of the different concentrations of $V$. rotundifolia were added to $495 \mu$ l of DPPH in absolute ethanol solution $(0.25 \mathrm{mM})$. After incubation for $20 \mathrm{~min}$ at room temperature, the absorbance of each solution was determined at $520 \mathrm{~nm}$ using microplate reader (GENios, Tecan).

\section{Superoxide scavenging by NBT method}

The superoxide scavenging ability of $V$. rotundifolia was studied using xanthine/xanthine oxidase/ NBT method according to Ibrahim et al. (2007) with some modification. The reaction mixture contained $0.5 \mathrm{ml}$ of $1.6 \mathrm{mM}$ xanthine, $0.48 \mathrm{mM} \mathrm{NBT}$ in $10 \mathrm{mM}$ phosphate buffer ( $\mathrm{pH}$ 8.0). After pre-incubation at $37^{\circ} \mathrm{C}$ for $5 \mathrm{~min}$, the reaction was initiated by adding 1 $\mathrm{ml}$ of xanthine oxidase $(0.05 \mathrm{U} / \mathrm{ml})$ and incubation at $37^{\circ} \mathrm{C}$ for $20 \mathrm{~min}$. The reaction was stopped by adding $1 \mathrm{ml}$ of $69 \mathrm{mM}$ sodium dodecyl sulfate (SDS) and the absorbance at $570 \mathrm{~nm}$ was measured.

\section{Nitric oxide radical scavenging assay}

A $5 \mu \mathrm{l}$ aliquot of the different concentrations of $V$. rotundifolia were added to $495 \mu \mathrm{l}$ of sodium nitroprusside solution (5 mm). After incubation at room temperature for $150 \mathrm{~min}, 100 \mu \mathrm{l}$ aliquots were removed from reaction mixture and incubated 
with an equal volume of Griess reagent (1\% sulfanilamide, $0.1 \% \mathrm{~N}$ - (1-naphtyl) - ethylenediamine dihydrochloride, $\left.2.5 \% \mathrm{H}_{3} \mathrm{PO}_{4}\right)$. The absorbance was determined and the standard was determined by using sodium nitrite at $540 \mathrm{~nm}$.

\section{Peritoneal macrophage culture}

TG-elicited macrophages were harvested 3 - 4 days after i.p. injection of $2.5 \mathrm{ml}$ thioglycolate (TG) to the mice and isolated. Using $8 \mathrm{ml}$ of HBSS containing $10 \mathrm{U} / \mathrm{ml}$ heparin, peritoneal lavage was performed. Then, the cells were distributed in DMEM, which was supplemented with $10 \%$ heat-inactivated FBS, in 24-well tissue culture plates $\left(3 \times 10^{5}\right.$ cells/well) incubated for $3 \mathrm{~h}$ at $37^{\circ} \mathrm{C}$ in an atmosphere of $5 \%$ $\mathrm{CO}_{2}$, washed three times with HBSS to remove non-adherent cells and equilibrated with DMEM that contained $10 \%$ FBS before treatment.

\section{MTT assay}

Cell proliferation, an indicator of cell viability, was analysed by the mitochondrial dependent reduction of 3-(3, 4 - dimethylthiazol - 2-yl) -2, 5-diphenyl tetrazolium bromide (MTT) to formazan, as described by Mosmann (Mosmann, 1983). The extent of the reduction of MTT to formazan within cells was quantified by measuring the optical density (OD) at $540 \mathrm{~nm}$ using an automated microplate reader (GENios, Tecan, Austria).

\section{Assay of nitrite concentration}

Peritoneal macrophages $\left(3 \times 10^{5}\right.$ cells/well $)$ were cultured with various concentrations of $V$. rotundifolia. The cells were then stimulated with rIFN- $\gamma(20 \mathrm{U} /$ $\mathrm{ml})$. After $6 \mathrm{~h}$, the cells were finally treated with LPS $(10 \mu \mathrm{g} / \mathrm{ml})$. NO synthesis in cell cultures was measured by a Griess assay method. To measure nitrite, $100 \mu \mathrm{l}$ aliquots were removed from conditioned medium and incubated with an equal volume of Griess reagent at room temperature for $10 \mathrm{~min}$. The absorbance at $540 \mathrm{~nm}$ was determined by an automatic microplate reader. $\mathrm{NO}_{2}^{-}$concentration was determined by using sodium nitrite as a standard. The cell-free medium alone contained 5 to $9 \mathrm{M}$ of $\mathrm{NO}_{2}^{-}$. This value was determined in each experiment and subtracted from the value obtained from the medium with peritoneal macrophages.

\section{Western blot analysis}

Whole cell lysates were prepared by boiling peritoneal macrophages in sample buffer $(62.5 \mathrm{mM}$ Tris-HCl pH 6.8, 2\% sodium dodecyl sulfate (SDS), $20 \%$ glycerol and 10\% 2-mercaptoethanol). Proteins in the cell lysates were then separated by $10 \%$ SDSpolyacrylamide gel electrophoresis (SDS-PAGE) and transferred to nitrocellulose membrane. The membrane was then blocked with 5\% skim milk for $2 \mathrm{~h}$ at room temperature and then incubated with anti-iNOS (SantaCruz, USA). After washing with phosphate buffered saline (PBS) containing $0.05 \%$ tween 20 three times, the blot was incubated with secondary antibody (anti-rabbit IgG, anti-mouse $\operatorname{IgG}$ ) for $1 \mathrm{~h}$ and the antibody specific proteins were visualized by the enhanced chemiluminesence (ECL) detection system according to the recommended procedure (Amersham Corp. Newark, NJ, Germany).

\section{Statistical analysis}

All measurement are expressed as the mean \pm S.D. of independent experiments. Data between groups were analyzed by a paired students' $t$ test and $P$-values less than 0.01 were considered significant.

\section{RESULTS}

\section{Effects of $V$. rotundifolia on cell viability}

To determine the effects of $V$. rotundifolia on viability of mouse peritoneal macrophages, the we carried out MTT assay. When we treated the cells were treated with $V$. rotundifolia at the concentrations of $0.01,0.1,1 \mathrm{mg} / \mathrm{ml}$, it had no effect on cell viability. The incubation of mouse peritoneal macrophages with $V$. rotundifolia and $10 \mu \mathrm{g} / \mathrm{ml}$ LPS also did not shown any cytotoxicity (Fig. 1). 


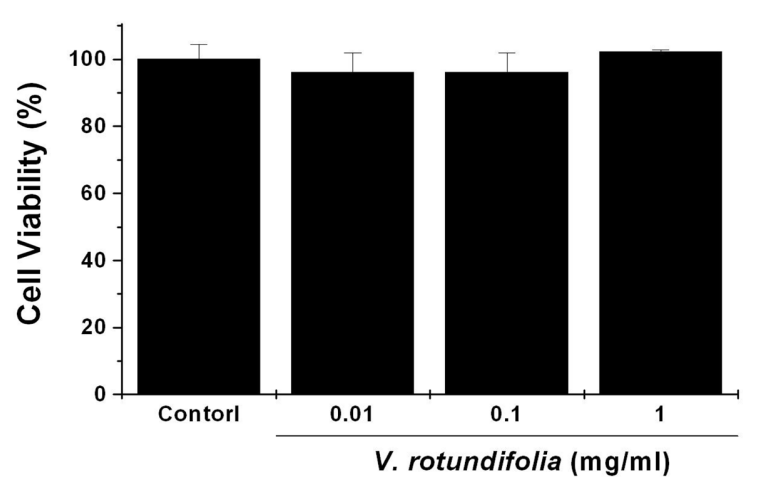

Fig. 1. Effects of $V$. rotundifolia on the viability in rIFN$\gamma /$ LPS stimulated peritoneal macrophages. Various concentrations of $V$. rotundifolia-treated peritoneal macrophages $\left(3 \times 10^{5}\right.$ cells/well $)$ were primed for $6 \mathrm{~h}$ with rIFN- $\gamma(20 \mathrm{U} / \mathrm{ml})$. The peritoneal macrophages were then stimulated with LPS $(10 \mu \mathrm{g} / \mathrm{ml})$ for $24 \mathrm{~h}$. Cell viability was evaluated by MTT colorimetric assay as described in the method. The results are expressed as means \pm S.D. of three independent experiments duplicate in each run.

\section{Inhibition of $V$. rotundifolia on NO production}

To determine the effect of $V$. rotundifolia on the production of NO in mouse peritoneal macrophages, nitrite accumulation was measured by the Griess reaction. The author pre-treated the cells in the presence or absence of various concentrations $V$. rotundifolia $(0.01,0.1$ and $1 \mathrm{mg} / \mathrm{ml})$. And then stimulated them with $\mathrm{rIFN}-\gamma(20 \mathrm{U} / \mathrm{ml})$ and LPS $(10 \mu \mathrm{g} / \mathrm{ml})$. The resultant $\mathrm{NO}$ production was determined by detecting nitrite concentrations in the cell supernatants after $48 \mathrm{~h}$ treatment. The amount of $\mathrm{NO}$ in unstimulated cells was $3.62 \pm 0.4$ $\mu \mathrm{M}$. When mouse peritoneal macrophages were primed for $6 \mathrm{~h}$ with murine $\mathrm{rIFN}-\gamma$ and then treated with LPS, NO production was increased about 10 folds $(36.2 \pm 0.45 \mu \mathrm{M})$. V. rotundifolia had few effect on NO production in resting mouse peritoneal macrophages compared to non-primed conditions. When $V$. rotundifolia was pre-treated in primed cell, $V$. rotundifolia significantly inhibits $\mathrm{NO}$ production dose dependently and over 64\% $(P<$ 0.01 ) inhibition of $\mathrm{NO}$ production was shown at the concentration of $1 \mathrm{mg} / \mathrm{ml}$ (Fig. 2). No significant effect on cell viability was observed at a test

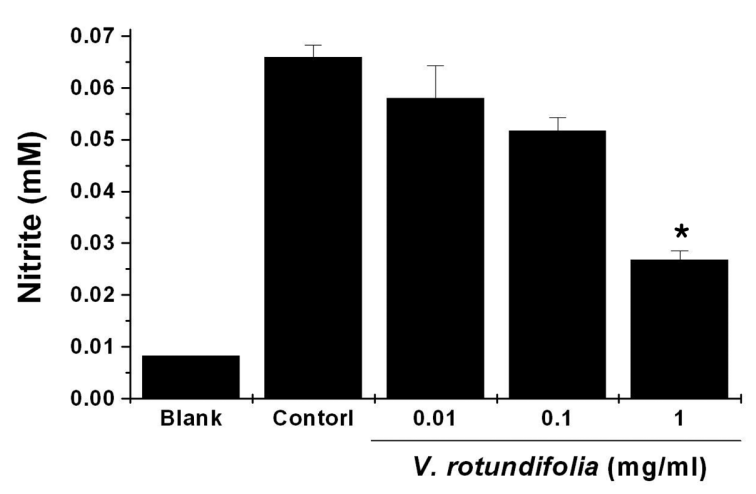

Fig. 2. Effects of $V$. rotundifolia on NO inhibition in rIFN- $\gamma$ and LPS-stimulated peritoneal macrophages. Peritoenal macrophages $\left(3 \times 10^{5}\right.$ cells/well $)$ were cultured with various concentration $V$. rotundifolia. The peritoneal macrophages were then stimulated with rIFN- $\gamma(20 \mathrm{U} / \mathrm{ml})$ and LPS $(10 \mu \mathrm{g} / \mathrm{ml})$. After $48 \mathrm{~h}$ of culture, NO release was measured by the Griess method (nitrite). NO released into the medium is presented as the mean \pm S.D. of three independent experiments duplicate in each run ${ }^{*} P<0.01$ compared to $\mathrm{rIFN}-\gamma+$ LPS.

concentration up to $1 \mathrm{mg} / \mathrm{ml} V$. rotundifolia (Fig. 1). Therefore, the inhibitory effect of $\mathrm{NO}$ by $V$. rotundifolia was not due to a cytotoxicity on the cells.

\section{Effects of $V$. rotundifolia on expression of iNOS and COX-2}

In order to investigate the mechanism of action of $V$. rotundifolia on the inhibition of NO production, Western blotting was performed. We investigate the effect of the $V$. rotundifolia at translational level by western blotting, as shown in Fig. 4, the expression of iNOS and COX-2 protein were markedly increased after rIFN- $\gamma(20 \mathrm{U} / \mathrm{ml})$ plus LPS $(10 \mu \mathrm{g} / \mathrm{ml})$ challenge for $24 \mathrm{~h}$. This enhanced expression of iNOS protein was significantly reduced by $V$. rotundifolia in a dose-dependent manner (Fig. 3) and V. rotundifolia also inhibits expression of COX-2.

\section{Effects of $\boldsymbol{V}$. rotundifolia on activation of NF- $\mathrm{KB}$}

$\mathrm{NF}-\kappa \mathrm{B}$ is activated in cells stimulated with LPS and other inflammatory insults, a process that is related to the transcriptional activation of responsive genes. As shown in Fig. 4, the activation of NF- $\mathrm{BB}$ was 


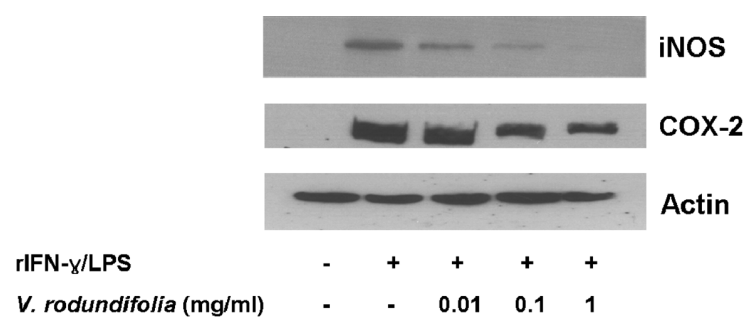

Fig. 3. Effects of $V$. rotundifolia on the expression of iNOS and COX-2 by rIFN- $\gamma /$ LPS activated peritoneal macrophages. Peritoneal macrophages $\left(5 \times 10^{6}\right.$ cells/ well) were pretreated with $V$. rotundifolia and then stimulated for 6 hour with $\operatorname{rIFN}-\gamma(20 \mathrm{U} / \mathrm{ml})$. The peritoneal macrophages were then stimulated with LPS $(10 \mu \mathrm{g} / \mathrm{ml})$ for $24 \mathrm{~h}$. The protein extracts were prepared; samples were analyzed for iNOS and COX2 expression by Western blotting as described in the method.

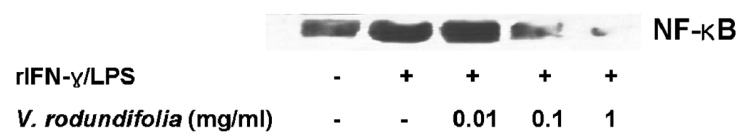

Fig. 4. Effects of V. rotundifolia on the activation of NF$\kappa \mathrm{B}$ by rIFN- $\gamma /$ LPS-stimulated peritoneal macrophages. Peritoneal macrophages $\left(5 \times 10^{6}\right.$ cells/well $)$ were pretreated with $V$. rotundifolia. After $30 \mathrm{~min}$, the cells were stimulated with $\mathrm{rIFN}-\gamma(20 \mathrm{U} / \mathrm{ml})$ for $30 \mathrm{~min}$. The peritoneal macrophages were then stimulated with LPS $(10 \mu \mathrm{g} / \mathrm{ml})$ for $2 \mathrm{~h}$. The nuclear extracts were prepared; samples were analyzed by Western blotting as described in the method.

markedly increased after rIFN- $\gamma(20 \mathrm{U} / \mathrm{ml})$ plus LPS $(10 \mu \mathrm{g} / \mathrm{ml})$ challenge for $10 \mathrm{~min}$. This increased expression of NF-kB was significantly reduced by V. rotundifolia (Fig. 4).

\section{Antioxidant activities of $V$. rotundifolia}

In order to investigate the antioxidant activities of $V$. rotundifolia, we performed three different in vitro assays such as DPPH radical, superoxide anion and nitric oxide scavenging methods. The radical scavenging activity was measured as decolorizing activity following the trapping of the unpaired electron of DPPH (Burda and Oleszec, 2001). V. rotundifolia showed relatively high DPPH radical scavenging activity, at the concentration of 1000 $\mu \mathrm{g} / \mathrm{ml}$ with $70.1 \pm 0.98 \%$ inhibition against DPPH radicals. As a control, ascorbic acid was used and $\%$ inhibition value obtained was $88.47 \pm 0.64 \%$ (Table 1). The superoxide radical was generated by the xanthine/xanthine oxidase system. Results from the NBT analysis revealed that $V$. rotundifolia had slight superoxide radical scavenging activity up to $100 \mu \mathrm{g} / \mathrm{ml}$. However, $1000 \mu \mathrm{g} / \mathrm{ml}$ of $V$. rotundifolia, showed strong superoxide radical scavenging activities similar to ascorbic acid (Table 1). Sodium nitroprusside (SNP) is known to produce nitric oxide and under aerobic conditions, nitric oxide reacts with oxygen to form nitrate and nitrite, which can be determined using Griess reagent. As shown in Table 1, V. rotundifolia inhibited nitrite production significantly and the its nitric oxide scavenging capacity was about $89 \%$ that of ascorbic acid.

\section{DISCUSSION}

In the present study, we evaluated the antiinflammatory effect on the production of inflammatory

Table 1. Scavenging capacity of $V$. rotundifolia in different free radical scavenging tests

\begin{tabular}{|c|c|c|c|c|}
\hline \multirow{2}{*}{ Treatment } & \multirow{2}{*}{ Concentration } & \multicolumn{3}{|c|}{ Radical scavenging capacity ${ }^{\mathrm{a}}$ (\% Inhibition) } \\
\hline & & DPPH & $\mathrm{X} / \mathrm{XO} / \mathrm{NBT}$ & Nitric oxide \\
\hline \multirow{3}{*}{ Ascorbic acid ${ }^{\mathrm{b}}(\mathrm{mM})$} & 0.01 & $25.73 \pm 6.86$ & ND & $8.66 \pm 1.29$ \\
\hline & 0.1 & $85.53 \pm 0.71$ & ND & $86.28 \pm 1.47$ \\
\hline & 1 & $85.94 \pm 0.75$ & $94.59 \pm 4.54$ & $97.97 \pm 0.11$ \\
\hline \multirow{3}{*}{$\begin{array}{l}\text { V. rotundifolia } \\
(\mu \mathrm{g} / \mathrm{ml})\end{array}$} & 0.01 & $4.33 \pm 3.25$ & $0.85 \pm 1.16$ & $1.58 \pm 0.95$ \\
\hline & 0.1 & $24.29 \pm 10.41$ & $25.96 \pm 7.51$ & $20.72 \pm 1.40$ \\
\hline & 1 & $71.98 \pm 2.50$ & $94.00 \pm 9.60$ & $78.96 \pm 0.32$ \\
\hline
\end{tabular}

${ }^{a}$ Each value in the table represents the mean \pm S.D of three parallel measurements. ${ }^{b}$ Ascorbic acid used as positive control. 
mediators in IFN- $\gamma$ and LPS stimulated murine peritoneal macrophages using $85 \% \mathrm{MeOH}$ extract of $V$. rotundifolia. And we also investigated its antioxidant properties using DPPH radical scavenging assay, superoxide scavenging asaay and nitric oxide radical scavenging assay.

$\mathrm{NO}$ is a free radical produced from L-arginine by NO NOS and maintaining diverse physiological homeostasis (Seo et al., 2001). However excess of NO cause many inflammatory diseases such as septic shock, neurologic disorders, rheumatoid arthritis and autoimmune diseases (Thiemermann and Vane, 1990). Therefore, we need to develop anti-inflammatory drug to inhibit overproduction of NO. In this study, we used IFN- $\gamma$ and LPS stimulated mouse peritoneal macrophage system to assess an inhibitory activities of $V$. rotundifolia on the pro-inflammatory mediators. As shown in Fig. 2 nitrite assay, determined by Griess method, indicated that the inhibition rates of $\mathrm{NO}$ production by $V$. rotundifolia were $32 \%, 75 \%$ and $86 \%$ at the concentration of $0.01,0.1,1 \mathrm{mg} / \mathrm{ml}$ respectively. Fig. 1 shows the potent inhibitory action of $V$. rotundifolia on $\mathrm{NO}$ production is not due to its cytotoxicity.

It is well known that excess production of $\mathrm{NO}$ is mediated by iNOS in activated macrophages. Suppression of iNOS expression levels might be an attractive therapeutic target for the treatment of NO-mediated inflammatory condition. V. rotundifolia strongly inhibited the expression of iNOS in a dose dependent manner (Fig. 3). This result explained that the inhibiton effect of $V$. rotundifolia on $\mathrm{NO}$ production was due to its suppressive activity on iNOS expression.

COX-2, an another key enzyme in inflammatory cascade, catalyze $\mathrm{PGE}_{2}$ synthesis from arachidonic acid (Minghetti et al., 1998). High levels of $\mathrm{PGE}_{2}$ take an important part in inflammatory conditions including asthma, rheumatoid arthritis and multiple sclerosis (Fitz Gerald et al., 2003). Since COX-2 is related with the synthesis of $\mathrm{PGE}_{2}$ an inflammatory mediator, inhibitors of COX-2 induction might candidates for the new type of nonsteroidal antiinflammatory drugs (NSAIDs). The possibility that $V$. rotundifolia might inhibit COX-2 expression was examined and $V$. rotundifolia suppressed the expression of COX-2 dose dependent manner (Fig. 3). Thus, it seems quite reasonable to speculate that $V$. rotundifolia may inhibits $\mathrm{PGE}_{2}$ production. However, further studies are required to determine whether $V$. rotundifolia is selective inhibitor of COX-2.

iNOS and COX-2 expression is regulated mainly at the transcriptional level and its major transcriptional regulator is the NF- $\mathrm{kB}$, which is also key regulators of a variety of genes involved in immune and inflammatory responese (Xie QW et al., 1994). In unstimulated cells, inactive NF-KB is sequestered in the cytoplasm and is linked to the inhibitory I $\mathrm{\kappa B}$ protein. However, in active state, following the induction of NF-кB by appropriate extracellular stimulation such as LPS, TNF- $\alpha$ or tissue plasminogen activator, it translocate to the nucleus with phosphorylation, ubiquitation and degradation of I $\mathrm{KB} \alpha$ and also acts upon the iNOS gene promoter to activate transcription. In this study, we investigated that the effect of $V$. rotundifolia on the translocation of NF-kB by using Western blotting. The result revealed that translocation of NF- $\mathrm{KB}$ to nucleus was attenuated especially at the concentration of $100 \mathrm{mg} / \mathrm{ml}$ (Fig. 4). These results indicate that the inhibition by $V$. rotundifolia on of the LPSstimulated expression of iNOS and COX-2 by blocking of NF- $\kappa B$ activation. It is expected that $V$. rotundifolia on may affect NF- $\mathrm{\kappa B}$ inducing kinase or IкB kinase activity. However, this hypothesis requires further investigation.

Free radicals such as ROS and RNS are highly reactive molecules and generated during normal metabolism process under aerobic conditions. They can damage lipids, proteins and DNA with oxidative stress. In immune cells such as macrophages have phagocytic function via secretion of free radical. In inflammatory condition, large amount of free redical is generated and it may cause several chronic inflammatory diseases such as atherosclerosis, 
rheumatoid arthritis (RA) and inflammatory bowel disease (IBD) (Bonomini et al., 2008). Therefore, a radical scavenger is useful for the treat of ROS and RNS mediated inflammatory diseases.

The radical scavenging activity of $V$. rotundifolia was determined from the reduction of absorbance at $520 \mathrm{~nm}$ due to scavenging of stable DPPH free radical. $V$. rotundifolia exhibited strong scavenging capacity compared with ascorbic acid (Table 1). We also investigated scavenging effect of $V$. rotundifolia on superoxide anion using $\mathrm{X} / \mathrm{XO} / \mathrm{NBT}$ system. $V$. rotundifolia was able to inhibit the formazan formation from NBT react with superoxide anion generated by xanthine oxidase system in a concentration dependent manner (Table 1). NO radical, a RNS, also can be a reason for oxidative stress (Ding et al., 1998). SNP mediated NO radical was reduced dose dependently by the $V$. rotundifolia (Table 1 ). Superoxide anion may react with $\mathrm{NO}$ radical resulting in the formation of peroxynitrite ( $\left.\mathrm{ONOO}^{-}\right)$, a powerful oxidant. In the present study, $V$. rotundifolia showed potent radical scavenging activities on superoxide anion and NO radical, and therefore, they may suppress peroxynitrite generation.

The production of NO, iNOS and COX-2 takes an important part of the immune response to many inflammatory stimulti. None the less, excessive overproduction of these mediators is implicated in acute and chronic inflammatory diseases including septic shock, hemorrhagic shock, multiple selerosis, rheumatoid arthritis, ulcerative colitis and atherosclerosis (Bertolini et al., 2003). In summary the present results demonstrate that the $V$. rotundifolia inhibits over production of $\mathrm{NO}$ in mouse peritoneal macrophages stimulated with LPS. This inhibitory effect was consistent with its down-regulation effect on the expression of iNOS in murine macrophages. Activation of NF- $\mathrm{KB}$ is thought play a key role in the LPS-stimulated expression of iNOS. $V$. rotundifolia also suppressed expression of COX-2 release through decreased NF- $\kappa \mathrm{B}$ transcriptional factor in a concentrationdependent manner. $V$. rotundifolia has not significant cytotoxicity at the treatment concentration. We also investigated the antioxidant properties of $V$. rotundifolia. The present study clearly revealed that $V$. rotundifolia has strong scavenging activity on DPPH radical, superoxide anion and NO radical. These results strongly suggest that $V$. rotundifolia may represent a potential new source of drugs for the treatment of ROS-mediated chronic inflammatory diseases as an effective immunomodulatory material.

\section{ACKNOWLEDGEMENTS}

This work was supported by the research gant from Woosuk University (2010).

\section{REFERENCES}

Bertolini A, Ottani A, Sandrini M. (2001) Dual acting anti-inflammatory drugs: a reappraisal. Pharmacol. Res. 44, 437-450.

Bonomini F, Tengattini S, Fabiano A, Bianchi R, Rezzani R. (2008) Atherosclerosis and oxidative stress. Histol. Histopathol. 23, 381-390.

Brune B, Zhou J, Von K. (2003) A Nitric oxide, oxidative stress, and apoptosis. Kidney Int. Suppl. 84, 22-24.

Burda S, Oleszek W. (2001) Antioxidant and antiradical activities of flavonoids. J. Agric. Food. Chem. 49, 2774-2779.

Conner EM, Grisham MB. (1996) Inflammation, free radicals, and antioxidants. Nutrition 12, 274-277.

Ding AH, Nathan CF, Stuerh DJ. (1998) Release of reactive nitrogen intermediates a $\mathrm{d}$ reactive oxtygen intermediates from mouse peritoneal macrophages. Comparison of activating cytokines and evidence of independent production. J. Immnol. 141, 2407-2412.

FitzGerald GA. (2003) COX-2 and beyond: approaches to prostaglandin inhibition in human disease. Nat. Rev. Drug Discov. 2, 879-890.

Gyamfi MA, Yonamine M, Aniya Y. (1999) Free-radical scavenging action of medicinal herbs from Ghana: Thonningia sanguinea on experimentally-induced liver injuries. Gen. Pharmacol. 32, 661-667.

Ibrahim HR, Hoq MI, Aoki T. (2007) Ovotransferrin possesses SOD-like superoxide anion scavenging activity that is promoted by copper and manganese binding. Int. J. Biol. Macromol. 41, 631-640. 
Ko WG, Kang TH, Lee SJ, Kim NY, Kim YC, Sohn DH, Lee BH. (2000) Polymethoxyflavonoids from Vitex rotundifolia inhibit proliferation by inducing apoptosis in human myeloid leukemia cells. Food Chem. Toxicol. 38, 861-865.

Lee YS, Han OK, Park CW, Yang CH, Jeon TW, Yoo WK, Kim SH, Kim HJ. (2005) Pro-inflammatory cytokine gene expression and nitric oxide regulation of aqueous extracted Astragali radix in RAW 264.7 macrophage cells. J. Ethnopharmacol. 100, 289-294.

Ono M, Yamamoto M, Masuoka C, Ito Y, Yamashita M, Nohara T. (1999) Diterpenes from the fruits of Vitex rotundifolia. J. Nat. Prod. 62, 1532-1537.

Minghetti L, Levi G. (1998) Microglia as effector cells in brain damage and repair: focus on prostanoids and nitric oxide. Prog. Neurobiol. 54, 99-125.

Mosmann T. (1983) Rapid colorimetric assay for cellular growth and survival: application to proliferation and cytotoxicity assays. J. Immunol. Methods 65, 55-63.

Saha K, Lajis NH, Israf DA, Hamzah AS, Khozirah S, Khamis S, Syahida A. (2004) Evaluation of antioxidant and nitric oxide inhibitory activities of selected Malaysian medicinal plants. J. Ethnopharmacol. 92,
263-267.

Shin TY, Kim SH, Lim JP, Suh ES, Jeong HJ, Kim BD, Park EJ, Hwang WJ, Rye DG, Baek SH, An NH, Kim HM. (2000) Effect of Vitex rotundifolia on immediate-type allergic reaction. J. Ethnopharmacol. 72, 443-450.

Thiemermann C, Vane J. (1990) Inhibition of nitric oxide synthesis reduces the hypotension induced by bacterial lipopolysaccharides in the rat in vivo. Eur. J. Pharmacol. 182, 591-595.

Wang T, El Kebir D, Blaise G. (2003) Inhaled nitric oxide in 2003: a review of its mechanisms of action. Can. J. Anaesth. 50, 839-846.

Xie QW, Kashiwabara, Nathan C. (1994) Role of transcription factor NF-kappa B/ Rel in induction of nitric oxide synthase. J. Biol. Chem. 269, 47054708.

Zamora R, Vodovotz Y, Billiar TR. (2000) Inducible nitric oxide synthase and inflammatory diseases. Mol. Med. 6, 347-373.

Zhu YP. (1998) Chinese Materia Medica Chemistry, Pharmacology and Applications. Harwood Academic Publishers, The Netherlands, 105-106. 